\title{
Entre a "fala que narra" e a "fala que demonstra": \\ Iniciativas em Arquivos de História Oral e o seu valor na construção das memórias e das identidades sociais
}

\author{
Between the word that we tell and the word that we \\ write:
}

\section{Initiatives in Oral History Archives and their value in the construction of social memories and identities}

\author{
Maria Cristina Vieira de Freitas ${ }^{1[O R C I D}$ 0000-0002-8849-8792] \\ ${ }^{1}$ Faculdade de Letras, Universidade de Coimbra, Arquivo da Universidade de Coimbra, Centro \\ de Estudos Interdisciplinares do Século XX - CEIS20, Portugal. \\ cristina.freitas@fl.uc.pt
}

\begin{abstract}
Resumo. Sociedades historicamente datadas experienciam as suas memórias coletivas ora guiadas pelos mitos ora conduzidas pela razão. $O$ texto fixa e retém a palavra num suporte e impõe padrões de comunicação distintos dos praticados no universo oral. No processo de construção das diversas identidades sociais relevam as relações de poder, produtos das divergências entre "incluídos" e "excluídos". Este estudo assenta-se nesses pressupostos teóricos. A abordagem é qualitativa, com caraterísticas exploratórias e descritivas. Recorre-se a fontes bibliográficas e documentais. Caraterizam-se cinco iniciativas que tipificam casos de constituição de Arquivos de História Oral, tendo como foco a organização, a representação e o acesso à informação. Os principais resultados apontam para: i) o uso de estratégias semelhantes de organização e de representação da informação, embora em níveis de conformidade diferenciados; ii) o respeito pelas regras impostas pelo direito de acesso aos conteúdos. A construção e a preservação da memória coletiva e a valorização do uso da História Oral servem como justificação para a existência dessas iniciativas. Pelas suas caraterísticas, este estudo limita-se a um conjunto restrito de casos, sugerindo-se o seu alargamento, bem como o aprofundamento das análises.
\end{abstract}

Palavras-chave: História oral; materiais especiais; organização da informação; representação da informação; memória coletiva.

\footnotetext{
Abstract. Societies that are historically dated experience their collective memories either guided by myths or led by reason. The text fixes and retains the words on a medium and imposes communication patterns that are different from the
} 
ones in the oral universe. In the process of constructing the different social identities, power relations are the product of the differences between the "included" ones and the "excluded" ones. This study is based on these theoretical assumptions. The approach is qualitative, with exploratory and descriptive characteristics. It uses bibliographical and documentary sources. It characterizes five initiatives that typify research cases of constitution of Oral History Archives, focusing on organization, representation, and access to information. The main results point to: i) the use of similar organization and information representation strategies, although at different levels of conformity; ii) the respect for the rules imposed by the right of access to the contents. The construction and preservation of the collective memory and the valorization of the use of Oral History serve as a justification for the existence of these initiatives. Due to its characteristics, this study is limited to a restricted set of cases, suggesting a future extension and the deepening of the analyzes.

Keywords: Oral history; special collections; information organization; information representation; collective memory.

\section{Introdução e enquadramento}

Há mais de um conceito para o termo "memória". Na sua sobejamente conhecida obra, traduzida, publicada e citada por diversos autores/as, em igualmente diversos idiomas, Le Goff (1984) diferencia uma memória individual, que é própria da capacidade humana de conservar a informação e que possui uma índole biológica, de uma outra, a memória social, que se sujeita aos grupos e às influências do meio. Ao procurar exemplos de sociedades historicamente datadas, que experienciam ou experienciaram o acesso à memória social, esse autor investiga, por um lado, as sociedades ágrafas, guiadas pelos "mitos", e, por outro, as sociedades da escrita, conduzidas pela "razão". Previamente aos estudos de Le Goff (1984), Halbwachs (1990) já havia fixado e analisado em profundidade o conceito de memória coletiva, admitindo também a existência do seu oposto complementar: a memória individual.

Traduzido como a "fala que narra", o termo mythos designa a forma como a consciência do eu e do outro se expressam no domínio da oralidade. Com efeito, a narrativa do mito é a que decorre de um tempo imemoriável, que fundamenta e fixa modelos exemplares de conduta social. É, pois, a "fala" primitiva e simbólica, acionada por mecanismos mnemónicos. Não se trata de uma explicação racional, destinada a satisfazer uma curiosidade intelectual, mas de uma narrativa que faz reviver uma realidade "primeira". Esse tipo de consciência coletiva tem um poder esmagador sobre as individualidades, na medida em que suspende os interesses pessoais e submete a pessoa ao grupo, sendo esta a sua caraterística ontológica mais evidente (Elíade, 1986; Gusdorf, 1979; Cunha, 1992; Malinowski, 1926). E a função desta "fala que narra" é oferecer explicações para os fenômenos e responder a perguntas que de outro modo ficariam sem resposta, projetando uma visão de mundo imersa numa espécie de perceção de grupo que carateriza o imaginário coletivo tecido no meio social.

Nestas sociedades, governadas pela consciência mítica, segundo Le Goff (1984), existem os guardiões e as guardiãs da memória, ou seja, pessoas autorizadas a preservar 
e a transmitir os mitos que contribuem para manter a coesão social. E essa transmissão não é feita ipsis verbis (Goody como citado em Le Goff, 1984, p. 430), mas pode atualizar-se e reatualizar-se a cada narrativa, conferindo liberdade e criatividade ao narrador/a. O valor desta transmissão não está, pois, na precisão da narrativa, mas na autenticidade e na fidedignidade, que se sustentam na crença e nos valores de quem narra. Le Goff (1984) se posiciona como um defensor da autenticidade dessa memória que se manifesta na oralidade e enumera as suas principais caraterísticas, entre as quais, o seu dinamismo, a sua naturalidade, o seu aspeto coletivo e o facto de ser socialmente construída e de ter um caráter dialético.

Igualmente, datado no tempo e no espaço, o vocábulo "logos" significa a "fala que demonstra" e que, como tal, descreve, governando-se por uma visão analítica e supostamente destituída de processos emocionais. Neste caso, a textualidade proporcionada pela escrita fixa e retém a palavra num suporte e impõe padrões de comunicação e de expressão que não se coadunam perfeitamente com aqueles que são próprios do contexto da oralidade. Para os seus críticos, essa rigidez e fixidez da palavra atinge o ápice na "Modernidade", atribuindo-se aos movimentos iluministas e positivistas a crença no poder explicativo da "razão" e a elevação do culto ao documento escrito como fonte ipsis litteris da verdade (Cunha, 1992; Thompson, 1992; Le Goff, 1984).

Esses aspetos são enfatizados por Le Goff (1984), para quem o aparecimento da escrita propicia o desenvolvimento de uma "memória da inscrição", vinculada às datas comemorativas e ao seu registo nos monumentos, ao lado de uma memória que é tangível no documento escrito e que passa a cumprir a dupla função de reter e de atualizar a informação, por meio do reexame e da retificação. Essa transformação tem um significado profundo e consubstancia-se na monumentalização da memória e do documento que, de meio para o ensino (docere $=$ ensinar), transforma-se em recurso para a recordação (monere $=$ recordar).

Essas transformações têm repercussões na constituição dos "monumentos de lembrança" - museus, bibliotecas e arquivos -, que cumprem a função de servir aos interesses da mentalidade de uma época e testemunham um projeto de civilização. No limite, a memória construída nas, e pelas, "sociedades da escrita" é "sequestrada" do espaço social e mantida como refém nesses lugares destinados à sua preservação, de uma forma não ritual e pouco identitária, visitando-se os "lugares como meios de memória" (De Decca,1992; Nora, 1993).

Essa distorção identitária tem consequências imediatas na desconexão das pessoas em relação aos bens que deveriam reconhecer como "o seu" património. As instituições, por seu turno, ao constituírem as suas próprias políticas de proteção desse património não levam em conta as identidades ou não respeitam as diferenças e os valores que enformam os grupos sociais. Estes, por seu turno, acabam por não querer ou não ter um acesso igualitário ao patrimônio que representa "a sua" cultura. Por conseguinte, o que se exprime como "patrimônio" e se constitui como um referencial identitário vem a ser fruto de uma apropriação indébita de um conceito, por uma minoria que se sobrepõe e silencia os interesses e as expetativas de uma maioria (Magnani, 1986; Paoli, 1992).

Essa apropriação nada tem do sentido original de "herança" ou de "bem comum". Para que o património possa imbuir-se de um significado cultural, ele deve exprimir-se por meio de valores de ordem afetiva, cognitiva, formal e pragmática (Meneses, 1992). 
E o ato de "autonomização do sujeito", que permite uma tomada de consciência acerca dos valores que enformam a sua própria identidade social, é um ato de "iluminação ética" (Morin, 1996). Todo esse processo de reconhecimento é, em si, um processo identitário.

Castells (1999, p. 22), define a identidade social como "o processo de construção de significado com base em um atributo cultural, ou ainda, um conjunto de atributos culturais inter-relacionados, o(s) qual(is) prevalece(m) sobre outras fontes de significado". Esses atributos constituem-se no património cultural. E no processo de construção das identidades sociais relevam, e já o dissemos, as relações de poder, que são produtos das divergências entre os "incluídos" e os "excluídos" desse processo. Nesta contenda forjam-se, segundo o mesmo Castells (1999), diferentes tipos de identidade, consoante os papeis e a perceção do grau de inclusão ou de exclusão do processo social: i) identidade legitimadora, que justifica, expande e racionaliza o poder das instituições dominantes; ii) identidade de legitimação, que se constrói em torno das pessoas excluídas do processo social, como uma forma de resistir à dominação; e iii) identidade de projeto, que se edifica em torno de um ideal comum e com vista a uma mudança social.

\section{$2 \quad$ Metodologia}

\subsection{Objetivos, fontes de dados e procedimentos}

No presente estudo exploramos e descrevemos iniciativas de constituição de Arquivos de História Oral [AHO] e discutimos a sua relevância na construção da(s) memória(s) e da(s) identidade(s) social(is).

A abordagem é qualitativa, quer pela forma como são selecionadas as amostras, intencionais e não probabilísticas (iniciativas nacionais e internacionais que se constituam em arquivos de história oral com presença na $W e b$ ), quer pela perspetiva analítica, recaindo o interesse nas caraterísticas, na variabilidade e nos significados implicados.

Neste estudo, recorremos a fontes bibliográficas e documentais. Primeiramente, selecionamos textos de índole científica, úteis à realização de um enquadramento do tema. $\mathrm{Na}$ escolha desses recursos, privilegiamos alguns textos considerados clássicos sobre a matéria. Seguidamente, selecionamos iniciativas que se constituem em AHO, visando a sua caraterização, em aspetos relacionados com a constituição, a organização e a representação da informação. Como desdobramento lógico, intentamos responder à seguinte questão de investigação: se, e de que modo, as estratégias de organização e de representação da informação contribuem para a construção e a preservação da memória e do património nos chamados AHO.

\section{Arquivos de História Oral: enquadramento e iniciativas}

As origens sistemáticas da História Oral [HO], segundo recorda Thompson (1992), situam-se nos Estados Unidos, no final da Segunda Grande Guerra, quando o seu uso terá sido impulsionado com o intuito de percecionar, através de relatos feitos na primeira 
pessoa, os problemas e as angústias enfrentadas pelos soldados envolvidos nas frentes de batalha. Conforme expressam Freitas e Silva (2016), na literatura científica internacional e de âmbito arquivístico, há uma tendência para o crescimento dos estudos dedicados à valorização da memória coletiva e do papel das comunidades no desenvolvimento, juntamente com os arquivos, de coleções que revelem as suas identidades, sendo esse um aspeto definidor do seu "empowerment", ou seja, da sua autonomia e da sua emergência enquanto comunidade (Morin, 1996). Todo esse pluralismo compreendese melhor à luz do respeito pelo direito à diversidade e, conseguintemente, da valorização das distintas identidades que compõem o tecido social (Castells, 1999; Morin, 1996).

$\mathrm{Na}$ atualidade, segundo as nossas pesquisas, os exemplos de AHO são variados, pelo que abordaremos apenas algumas dessas iniciativas, procurando realçar as suas particularidades e captar alguma diversidade eventualmente existente.

A primeira iniciativa a reportar é a que desenvolve o National Archives and Records Administration [NARA $]^{1}$.Trata-se de uma página alojada no sítio $W e b$ da instituição, para a qual são vertidas as transcrições das várias entrevistas realizadas com personalidades do meio arquivístico ligadas à instituição. Estas entrevistas são o resultado de um Projeto intitulado National Archives Oral History [NAOHP], desenvolvido com o intuito de recolher os depoimentos dos seus atuais e antigos colaboradores. Os conteúdos desses depoimentos versam sobre experiências, ideias e perspetivas das pessoas entrevistadas, no âmbito do seu trabalho em arquivos e no contexto em que o mesmo se desenvolveu. Com esse projeto, e segundo na própria página se indica, o NARA (2019) pretende compreender a sua própria cultura organizacional, por meio da identificação de práticas, tomadas de decisão, ações e eventos históricos e preservar uma parte da memória institucional. Trata-se de um projeto incremental, interativo e colaborativo, em que a comunidade pode sugerir novas pessoas a entrevistar e novos/as entrevistadores/as. Quanto à organização, a informação está classificada primeiramente pelos tipos de entrevistas e/ou entrevistadores e, seguidamente, ordenada pelos nomes das pessoas entrevistadas, dispondo-se estes na ordem direta. Os conteúdos das entrevistas encontram-se resumidos e, em alguns casos, são acompanhados pela fotografia da pessoa entrevistada. As gravações das entrevistas não se encontram, atualmente, disponíveis nessa página. As transcrições incluem os correspondentes termos de autorização para a comunicação do conteúdo. Presentemente, na página oficial do projeto contam-se 40 entrevistas realizadas entre os anos de 1972 e 2017, com personalidades relevantes para a história da Arquivística norte-americana e internacional (e.g., Lester Cappon, Oliver Holmes, Ernst Posner e Philip Bauer) e com arquivistas menos conhecidos/as do público específico. Os conteúdos são reveladores de aspetos singulares da sua carreira profissional e partilhados em livre acesso, podendo ser utilizados em investigações. Não se observam campos descritivos normalizados nas descrições apresentadas (figura $1)$.

\footnotetext{
${ }^{1}$ Disponível em: https://www.archives.gov/about/history/oral-history-at-the-national-archives.
} 


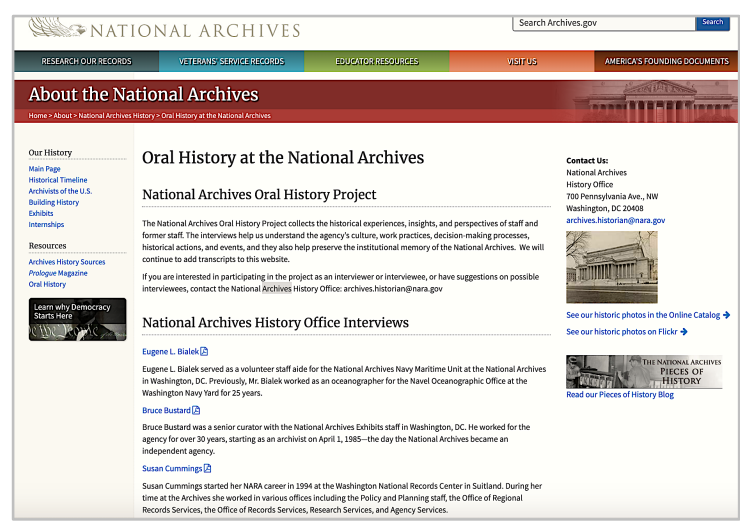

Figura 1. Instantâneo da página do projeto de HO do NARA.

Fonte. Disponível em: https://www.archives.gov/about/history/oral-history-at-the-national-archives.

A segunda iniciativa a descrever é o projeto desenvolvido pelo The Scottish Oral History Centre [SOHC] que, segundo as informações facultadas pela instituição (SOHC, 2019), estabeleceu-se no Departament of History of University of Strathclyde (Escócia), no ano de 1995, com o objetivo de fomentar atividades de ensino, pesquisa e extensão, no âmbito do uso da HO. Ainda, segundo se informa (SOHC, 2019), os recursos que compõem o fundo situam-se no período de 1981 até ao presente e em termos de descrição física ocupam $220 \mathrm{~GB}$ de espaço de armazenamento. Trata-se, pois, de um arquivo composto por recursos digitais. Pelos seus dados descritivos normalizados, verificamos que o The Scottish Oral History Centre Archive [SOHCA], instituição encarregada da organização, da representação e da comunicação dessa iniciativa, dispõe de uma ampla coleção de depoimentos cujos conteúdos, segundo as informações descritivas disponibilizadas, encontram-se associados à história do trabalho, da saúde ocupacional e dos impactos sociais provocados pelo fenómeno da desindustrialização na Escócia ${ }^{2}$ (SOHCA, 2019). Os recursos encontram-se organizados num primeiro nível em função dos projetos desenvolvidos pelos grupos de investigação, ordenados sequencialmente. Dentro de cada projeto, os dossiês ou processos são ordenados obedecendo a uma codificação numérica e sequencial, combinando-se esta com a referenciação dos nomes das pessoas entrevistadas, atribuídos em ordem direta, seguidos, em alguns casos, da sua data de nascimento ou da sua profissão. Diversos dos conteúdos são considerados sensíveis, pelo que o acesso em alguns casos pode não ser possível, estando esta restrição devidamente sinalizada. $\mathrm{O}$ acesso aos diferentes projetos, às descrições e, em alguns casos, às respetivas transcrições das entrevistas, é dado na zona destinada à indicação da existência de documentação relacionada, no formulário de descrição do fundo, disponibilizando-se os respetivos enlaces em forma de lista. A descrição realiza-se em campos que seguem as normas internacionais aconselhadas pelo Conselho Internacional de Arquivos [CIA], verificando-se o uso do software livre $A c$ cess to Memory [AtoM] para o efeito (figura 2).

\footnotetext{
${ }^{2}$ Disponível em: https://atom.lib.strath.ac.uk/sohc-archive;isad?sf_culture=pt.
} 


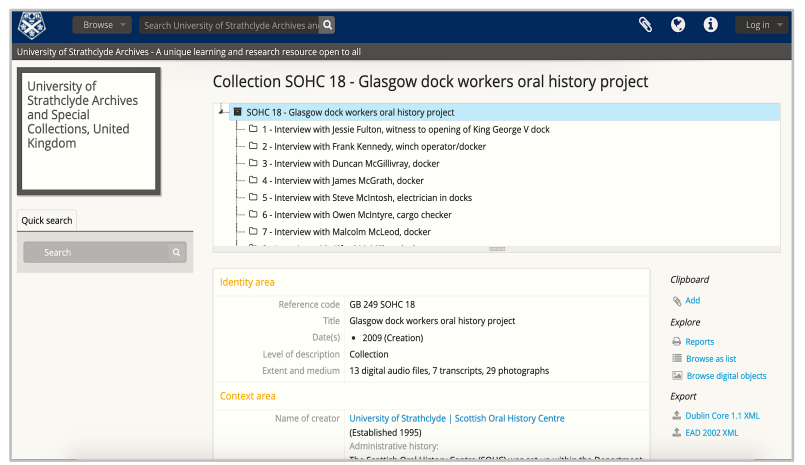

Figura 2. Instantâneo da descrição de um dos projetos de HO desenvolvidos pelo SOHC.

Fonte. Disponível em: https://atom.lib.strath.ac.uk/glasgow-dock-workers-oral-history-project;isad?sf_culture $=$ en.

A terceira iniciativa a indicar é a da University of Yale [UY], composta por 254 caixas contendo gravações e transcrições produzidas, segundo descreve a própria instituição (UY, 2019) 3 , no âmbito do projeto designado Yale-United Nations Oral History Project [YUNOHP], que documenta eventos considerados significativos para a história da UNESCO. As entrevistas são realizadas com personalidades proeminentes de vários países (políticos/as, embaixadores/as, diplomatas, etc.), para além de outros/as participantes. As datas-limite das entrevistas coligidas, segundo informa a UY (2019), são 1983 e 2005, não se prevendo ingressos adicionais. O acesso físico às cópias de uso desses recursos é livre, desde que sem fins comerciais. Pelo que se verifica, a coleção se encontra descrita, mas os recursos correspondentes não se encontram disponíveis para o livre acesso online. Quanto à organização, verifica-se, primeiramente, a classificação da informação pelo gênero documental (Transcripts; Tapes) e, seguidamente, a ordenação alfabética dos recursos pelo nome do/a entrevistado/a, na forma inversa. O software usado para a divulgação da coleção é o ArchiveSpace ${ }^{4}$, de uso livre (figura 3).

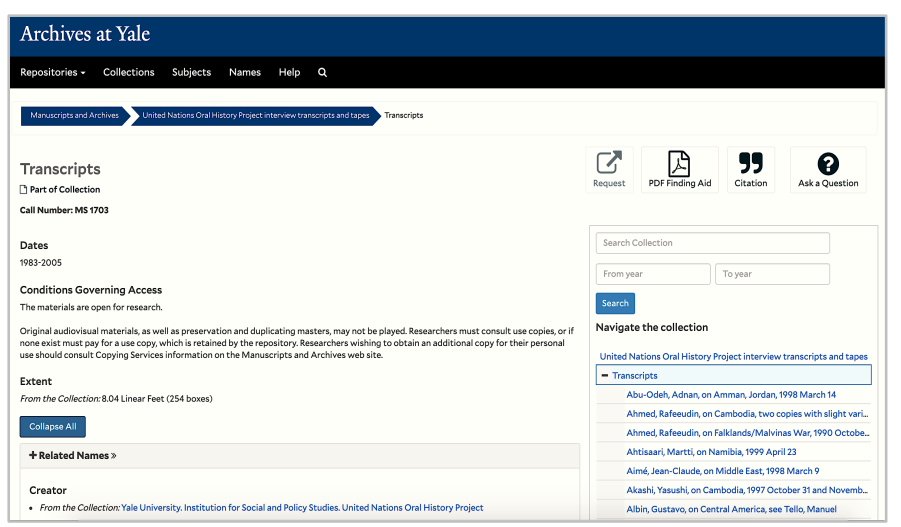

Figura 3. Instantâneo da descrição do projeto YUNOHP.

Fonte. Disponível em: https://archives.yale.edu/repositories/12/archival_objects/1256540.

\footnotetext{
${ }^{3}$ Disponível em: https://archives.yale.edu/repositories/12/resources/3915\#.

${ }^{4}$ Segundo a informação disponível no Website do ArchiveSpace. A plataforma do projeto não dá os devidos créditos no rodapé. Disponível em: https://archivesspace.org/community/whos-using-archivesspace.
} 
A quarta iniciativa a realçar é a da Oral History and Folklore Collection [OHFC], desenvolvida pela National Library of Australia [NLA]. Na sua página de divulgação ${ }^{5}$, a NLA (2019) refere que o principal objetivo a cumprir com o desenvolvimento desta coleção é recolher uma série de registos de distintas manifestações artísticas e culturais do país (estórias, músicas, danças, etc.), para além dos depoimentos recolhidos de personalidades reconhecidas (cientistas, escritores, políticos, artistas, etc.) e de pessoas que vivenciam diversas situações e/ou representam diversas tendências sociais (imigrantes, refugiados, desempregados, etc.). A coleção, cujas gravações mais antigas datam de 1950, reflete a vida social, cultural e intelectual do país e tem uma extensão, segundo se informa, de 45.000 horas gravadas, encontrando-se aberta à inclusão de novos itens (NLA, 2019). Verificamos que os recursos estão descritos, no catálogo, item por item, encontrando-se disponíveis os respetivos registos bibliográficos. Também verificamos, seguindo o enlace que dá acesso direto aos itens da coleção, que os conteúdos se encontram reunidos num único ponto de acesso. As entrevistas, segundo os dados informados (NLA, 2019), são descritas como recurso integrante dos projetos desenvolvidos ou como itens individuais da coleção, se o caso não é o anterior. Algumas entrevistas vêm acompanhadas por um resumo não estruturado e de tamanho variável, incluído também no catálogo. As gravações e as transcrições também podem ser acedidas pelo mesmo catálogo, juntamente com as descrições às quais se encontram associadas. $\mathrm{O}$ acesso é aberto para a pesquisa e o uso pessoal e não comercial, na maioria dos itens da coleção. Naturalmente, alguns desses itens são de acesso reservado (figura 4).

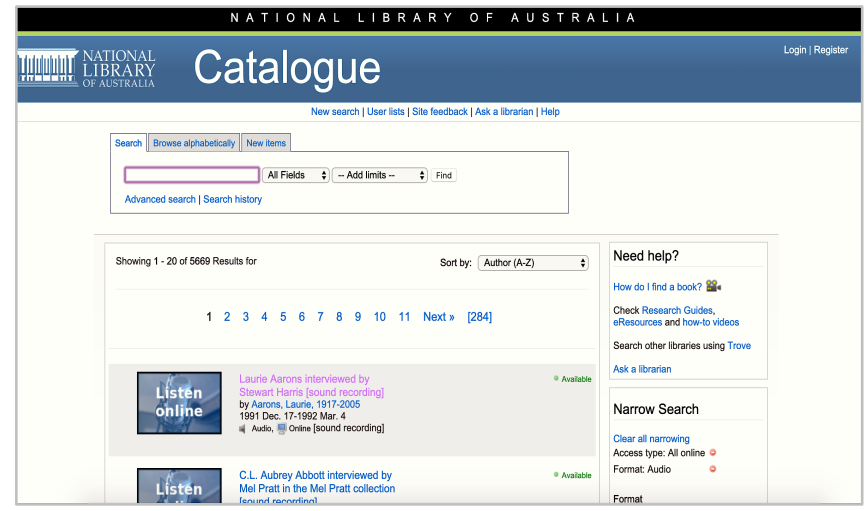

Figura 4. Instantâneo da descrição das entrevistas na coleção de HO da NLA.

Fonte. Disponível em: https://catalogue.nla.gov.au/Search/Home?lookfor $=\&$ filter $\% 5 b \% 5 d=a c-$ cess_type $\% 3 \mathrm{~A} \% 22 \mathrm{All} \% 20$ online $\% 22 \&$ type $=$ Array\&narrow $=1 \&$ filter $\% 5 \mathrm{~b} \% 5 \mathrm{~d}=$ format: $\% 22 \mathrm{Au}-$

dio $\% 22 \&$ sort $=$ sort_date_asc\&sort $=$ sort_date_desc\&page $=1 \&$ sort $=\&$ page $=1 \&$ sort $=$ sort_date_desc $\&$ page $=1$ $\&$ sort=sort_author_asc\&page $=1$.

A quinta iniciativa a mencionar é a Oral History Collections [OHC] constituída no âmbito do Center for Oral History [COH], pertencente ao Science History Institute [SHI]. Segundo informa o próprio SHI (2019) ${ }^{6}$, trata-se de uma coleção que contém centenas de entrevistas consideradas relevantes para o estudo de diversos temas associados à história da ciência, da medicina e da tecnologia. As entrevistas começaram a

\footnotetext{
${ }^{5}$ Disponível em: https://www.nla.gov.au/what-we-collect/oral-history-and-folklore.

${ }^{6}$ Disponível em: https://www.sciencehistory.org/oral-history-collections.
} 
ser produzidas no ano de 1979. Entre as personalidades ilustres, que figuram no rol de entrevistados/as, encontram-se cientistas laureados/as com o Prêmio Nobel (e.g., Alan MacDiarmid e David Baltimore) e outros/as que foram medalhados/as pela National Medal of Science. As gravações e as transcrições podem ser de acesso livre ou restrito, dependendo da sensibilidade dos conteúdos. Para obter as transcrições das entrevistas que se encontram em livre acesso, deve-se preencher um rápido formulário. $\mathrm{O}$ download é gratuito e imediato. Nesta coleção, segundo se observa, as entrevistas estão organizadas individualmente ou no âmbito de projetos de ciência. No primeiro caso, estão ordenadas alfabeticamente pelo nome da pessoa entrevistada, disposto em ordem direta. No segundo caso, a ordenação também é a alfabética, mas pelo nome do projeto (figura 5). O software usado para a divulgação, segundo apuramos, é também o ArchiveSpace ${ }^{7}$.

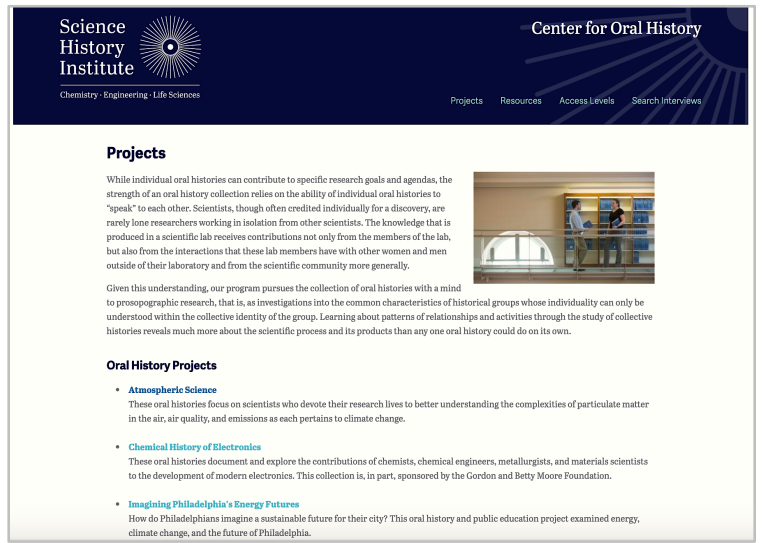

Figura 5. Instantâneo da descrição de um dos projetos desenvolvidos pelo SHI. Fonte. Disponível em: https://oh.sciencehistory.org/oral-histories/projects.

\section{Discussão e conclusões}

Este estudo explorou, em linhas gerais, o tríplice e historicamente datado conceito de memória social, que é construído, segundo Le Goff (1984), no contexto da oralidade (dinâmica, social e inclusiva) e no contexto da textualidade (estática, individual e exclusiva). Trata-se de manifestações cíclicas experienciadas em diferentes momentos e realidades sociais. A esse conceito tridimensional associam-se as tipificações fornecidas por Castels (1999), para quem as identidades sociais manifestam-se também em diferentes aceções (legitimadora, de legitimação e de projeto), dependendo das relações de poder que se estabelecem e que resultam, na sua constituição, nos processos de inclusão ou, contrariamente, de exclusão dos diversos grupos sociais.

Este estudo também identificou diversas iniciativas de constituição de coleções de HO, em desenvolvimento em diferentes países, desde a década de 1950. Dessas iniciativas, foram selecionadas apenas cinco, usadas para tipificar casos, apoiando-se no

\footnotetext{
${ }^{7}$ Segundo a informação disponibilizada no Website deste software, uma vez que a plataforma não dá os devidos créditos no seu rodapé. Disponível em: https://archivesspace.org/community/whos-using-archivesspace.
} 
critério da variabilidade, com a expetativa de atingir alguma riqueza na descrição e na análise dos resultados (quadro 1).

Quadro1. Comparativo das informações descritivas facultadas pelos projetos de AHO selecionados

\begin{tabular}{|c|c|c|c|}
\hline $\begin{array}{l}\text { Identificação, lo- } \\
\text { calização e datas- } \\
\text { limite }\end{array}$ & Principais objetivos & $\begin{array}{l}\text { Organização/repre- } \\
\text { sentação da informa- } \\
\text { ção }\end{array}$ & $\begin{array}{l}\text { Acesso e divulgação da } \\
\text { informação }\end{array}$ \\
\hline $\begin{array}{l}\text { National Archives } \\
\text { and Records Ad- } \\
\text { ministration. } \\
\text { EUA. } \\
1972 \text { - . }\end{array}$ & $\begin{array}{l}\text { Documentar as experiên- } \\
\text { cias em torno do trabalho } \\
\text { em arquivos. } \\
\text { Compreender a cultura or- } \\
\text { ganizacional e preservar a } \\
\text { memória institucional. }\end{array}$ & $\begin{array}{l}\text { Pelos tipos de entrevis- } \\
\text { tas/entrevistadores/as e } \\
\text { pelo nome do/a entre- } \\
\text { vistado/a, em ordem } \\
\text { direta; oferece resumos } \\
\text { sinaléticos. }\end{array}$ & $\begin{array}{l}\text { Acesso livre e online. } \\
\text { Webpage alojada em } \\
\text { Website oficial da insti- } \\
\text { tuição. }\end{array}$ \\
\hline $\begin{array}{l}\text { The Scottish Oral } \\
\text { History Centre Ar- } \\
\text { chive, University } \\
\text { of Strathclyde. } \\
\text { Reino Unido } \\
\text { (Escócia). } \\
\text { 1981- . }\end{array}$ & $\begin{array}{l}\text { Fomentar atividades de en- } \\
\text { sino, pesquisa e extensão, } \\
\text { no âmbito da HO. } \\
\text { Documentar a história do } \\
\text { trabalho, da saúde ocupaci- } \\
\text { onal e os impactos sociais } \\
\text { do fenómeno da desindus- } \\
\text { trialização. }\end{array}$ & $\begin{array}{l}\text { Pelo nome das pessoas } \\
\text { entrevistadas, em or- } \\
\text { dem direta; oferece re- } \\
\text { sumos sinaléticos. }\end{array}$ & $\begin{array}{l}\text { Acesso livre e online, } \\
\text { com restrição para os } \\
\text { conteúdos sensíveis. } \\
\text { Software AtoM. }\end{array}$ \\
\hline $\begin{array}{l}\text { Yale-United Na- } \\
\text { tions Oral History } \\
\text { Project, Univer- } \\
\text { sity of Yale. } \\
\text { EUA. } \\
1983-2005 .\end{array}$ & $\begin{array}{l}\text { Documentar eventos signi- } \\
\text { ficativos para a história da } \\
\text { UNESCO. }\end{array}$ & $\begin{array}{l}\text { Pelo gênero documen- } \\
\text { tal e pelo nome das } \\
\text { pessoas entrevistadas, } \\
\text { em ordem inversa. }\end{array}$ & $\begin{array}{l}\text { Acesso livre e local às } \\
\text { cópias de uso. Acesso } \\
\text { online às descrições ar- } \\
\text { quivísticas. } \\
\text { Software ArchiveSpace. }\end{array}$ \\
\hline $\begin{array}{l}\text { National Archives } \\
\text { Oral History, Na- } \\
\text { tional Library of } \\
\text { Australia. } \\
1950 \text { - }\end{array}$ & $\begin{array}{l}\text { Registar distintas manifes- } \\
\text { tações artísticas e culturais } \\
\text { do país, pela voz de perso- } \\
\text { nalidades reconhecidas e de } \\
\text { pessoas que vivenciam situ- } \\
\text { ações e/ou representam ten- } \\
\text { dências sociais. }\end{array}$ & $\begin{array}{l}\text { Pelo nome das pessoas } \\
\text { entrevistadas, em or- } \\
\text { dem direta, ou pelo } \\
\text { projeto; alguns resu- } \\
\text { mos sinaléticos são } \\
\text { oferecidos. }\end{array}$ & $\begin{array}{l}\text { Acesso live e online, } \\
\text { com restrição para os } \\
\text { conteúdos sensíveis. } \\
\text { Webpage de divulgação } \\
\text { da coleção mantém liga- } \\
\text { ção ao catálogo biblio- } \\
\text { gráfico. }\end{array}$ \\
\hline $\begin{array}{l}\text { Center for Oral } \\
\text { History, Science } \\
\text { History Institute. } \\
\text { EUA. } \\
1979-\quad .\end{array}$ & $\begin{array}{l}\text { Registar os relatos de per- } \\
\text { sonalidades relevantes para } \\
\text { o estudo da história da ciên- } \\
\text { cia, da medicina e da tecno- } \\
\text { logia. }\end{array}$ & $\begin{array}{l}\text { Pelo nome das pessoas } \\
\text { entrevistadas, em or- } \\
\text { dem direta, ou pelo } \\
\text { projeto; alguns resu- } \\
\text { mos sinaléticos são } \\
\text { oferecidos. }\end{array}$ & $\begin{array}{l}\text { Acesso livre e online, } \\
\text { mediante preenchimento } \\
\text { de formulário para per- } \\
\text { missão de download } \\
\text { imediato. Restrição de } \\
\text { acesso aos conteúdos } \\
\text { sensíveis. } \\
\text { Software ArchiveSpace. }\end{array}$ \\
\hline
\end{tabular}

Fonte. Dados produzidos pela investigação.

A partir do quadro 1, verificamos que algumas dessas iniciativas são encabeçadas por bibliotecas, outras por aquivos universitários ou nacionais, outras, ainda, por centros de estudos e de investigação. A maioria destes projetos está em curso (NLA; SHI; US; NARA) e possui uma longevidade compatível com o próprio aparecimento da $\mathrm{HO}$ enquanto método de investigação histórica. Maioritariamente, as iniciativas selecionadas encontram-se nos EUA, país que é considerado o berço do movimento pelo uso da HO como método histórico. Algumas das instituições que abrigam estas iniciativas são de âmbito público e nacional, outras são ligadas a universidades e outras, ainda, são 
organizações sem fins lucrativos. Essa relativa variabilidade não foi conferida aleatoriamente. Contrariamente, atendeu aos imperativos metodológicos do estudo.

Quanto aos objetivos, constatamos que há projetos dedicados a uma realidade institucional (NARA; UY), ao lado de projetos desenvolvidos com fins que ultrapassam esses limites, reportando-se ao contexto envolvente (NLA; SHI; US). Os objetivos enunciados oferecem como tronco comum a necessidade de documentar relatos, eventos, experiências e manifestações, tendo como perspetiva as pessoas envolvidas e como pano de fundo a memória coletiva, na aceção de Halbwachs (1990), e as diferentes identidades que participam no seu processo de construção, que importa documentar e preservar (quadro 1).

Nos AHO analisados, de um modo geral, notam-se mais semelhanças do que diferenças na forma de comunicar a informação. Assim, verifica-se que a maioria dos conteúdos, disponibilizados em plataformas gratuitas, são de acesso aberto e online, desde que não haja nenhuma restrição imposta (i.e., dados sensíveis). Quanto à organização e à representação da informação, podemos subdividir essas iniciativas em dois grupos. Há, por um lado, projetos com uma conceção menos complexa (NARA; NLA) e que, entretanto, encontram-se razoavelmente estruturados, na medida em que o/a utilizador/a descobre rapidamente a informação que pretende e compreende facilmente a forma de organização e de representação dos conteúdos. Por outro lado, há projetos um pouco mais robustos, encabeçados por Universidades e por Centros de Investigação, cujos objetivos são também, e principalmente, de natureza científica e que, por isso mesmo, recorrem a um registo diferente (UY; US; SHI). Trata-se de iniciativas com uma projeção longitudinal, que lidam com um volume de documentos mais substantivos, constituídos em torno de projetos de investigação, extensão e/ou ensino, cujos resultados são disponibilizados pelos respetivos arquivos institucionais, amparando-se em tecnologias e softwares conformes e adotando estruturas de dados descritivos que obedecem às normas e às convenções internacionais arquivísticas para a organização e a representação da informação (quadro 1). Nota-se, ademais, na conceção desses projetos, uma forte influência das diretrizes emanadas, no passado, do estudo pertencente à série RAMP, produzido por Moss e Mazikana (1986) e dedicado aos AHO.

Pelo exposto, e respondendo à questão inicial, conclui-se que as estratégias de organização e de representação da informação adotadas por estas instituições, ainda que em diferentes níveis de maturidade, oferecem um interessante e relevante contributo para a construção e a preservação da memória e do património, na medida em que disponibilizam, online, um conjunto de conteúdos credíveis, utilizáveis e reutilizáveis. Estas iniciativas também respeitam as regras impostas pelo direito de acesso, na medida em que os conteúdos considerados sensíveis, e que pelo que pudemos apurar serão a minoria dos casos observados, não se encontram disponíveis. Também, e naturalmente, são recolhidas as devidas autorizações para a divulgação do material produzido.

Como recomendação final e tendo em conta que, pelas suas caraterísticas, este estudo limita-se a um conjunto restrito de casos, sugere-se no futuro, o seu alargamento, bem como o aprofundamento da análise de outros aspetos relativos à organização e à representação da informação não abordados por este estudo. 


\section{Referências}

Castells, M. (1999). O poder da identidade (vol. 2). São Paulo: Paz e Terra.

Cunha, J. A. (1992) Filosofia: iniciação à investigação filosófica. São Paulo: Atual.

De Decca, E. S. (1992). Memória e cidadania. In: Secretaria Municipal de Cultura de São Paulo. Departamento de Patrimônio Histórico. O direito à memória: patrimônio histórico e cidadania (p. 129-138). São Paulo: DPH.

Elíade, M. (1986). Mito e realidade. São Paulo: Perspectiva.

Freitas, M. C. V. de, \& Silva, C. G. da. (2016). O novo e o atual na Arquivística internacional: a desmaterialização, a interoperabilidade, a organização e o uso da informação em evidência (2011-2016). In Actas do XII Encontro de Arquivos Municipais: Arquivos municipais: o que há de novo? Castelo Branco: APBAD. Recuperado de: http://www.bad.pt/publicacoes/index.php/arquivosmunicipais/article/view/1560/1470.

Gusdorf, G. (1979). Mito e metafísica. São Paulo: Convívio.

Halbwachs, M. (1990). A memória coletiva. São Paulo: Vértice.

Le Goff, J. (1984). História e memória. Campinas: UNICAMP.

Magnani, J. G. C. (1986). Pensar grande o patrimônio cultural. Lua Nova, 3(2), 62-67.

Malinowski, B. (1926). Myth in primitive psychology. New York: W.W. Norton \& Company.

Meneses, U. B. de. (1992). O patrimônio cultural entre o público e o privado. In: Secretaria Municipal de Cultura do Estado de São Paulo. Departamento de Patrimônio Histórico. O direito à memória: patrimônio histórico e cidadania (p.189-96). São Paulo: DPH.

Morin, E. (1996). A noção de sujeito: novos paradigmas, cultura e subjetividade. São Paulo: Artes Médicas.

Moss, W., \& Mazikana, P. (1986). Archives, oral history and oral tradition: a RAMP study. Paris: UNESCO.

National Archives and Records Administration - NARA. (2019). Oral history at National Archives. Disponível em: https://www.archives.gov/about/history/oral-history-at-the-nationalarchives.

National Library of Australia - NLA. (2019). Oral History and Folklore. Disponível em: https://www.nla.gov.au/what-we-collect/oral-history-and-folklore.

Nora, P. (1993). Entre história e memória: a problemática dos lugares. Revista Projeto História, $10,7-28$.

Paoli, M. C. (1992). Memória, história e cidadania: o direito ao passado. In: Secretaria Municipal de Cultura do Estado de São Paulo. Departamento de Patrimônio Histórico. O direito à memória: patrimônio histórico e cidadania (p. 25-28). São Paulo: DPH.

Science History Institute - SHI. (2019). Oral History Colletctions. Disponível em: https://www.sciencehistory.org/oral-history-collections. 
Scottish Oral History Centre, The - SOHC. (2019). Collection SOHC: Scottish Oral History Centre Archive. Disponível em: https://atom.lib.strath.ac.uk/sohc-archive;isad?sf_culture $=$ en.

Thompson, P. (1992). A voz do passado: história oral. Rio de Janeiro: Paz e Terra.

University of Yale - UY (2019). United Nations Oral History Project: interview transcripts and tapes. Disponível em: https://archives.yale.edu/repositories/12/resources/3915. 